\title{
Biology of Hippocampus patagonicus (Syngnathidae) in Brazilian waters. A species threatened with extinction, with suggestions for the conservation of seahorses in Brazil
}

\author{
Rosana Beatriz Silveira ${ }^{1}$, José Clebson da Silva ${ }^{1}$, Lua Benício ${ }^{1}$ \& José Rodrigo Santos Silva ${ }^{1,2}$ \\ ${ }^{1}$ Instituto Hippocampus, Porto de Galinhas, Ipojuca, Brazil \\ ${ }^{2}$ Departamento de Estatística e Ciências Atuárias, Universidade Federal de Sergipe \\ São Cristóvão, Brazil \\ Corresponding author: Rosana Beatriz Silveira (labaquac@yahoo.com)
}

\begin{abstract}
Specimens of Hippocampus patagonicus obtained in the bycatch of trawling in the states of Rio Grande do Sul (RS) and Rio de Janeiro (RJ) were collected in $2012(\mathrm{n}=199)$ and $2014(\mathrm{n}=157)$, respectively. Mean height of females of reproductive age in RS was $8.89 \pm 1.9 \mathrm{~cm}$, with the fecundity of $366 \pm 195.8$ eggs per clutch, and for males of reproductive age, height was $8.79 \pm 1.86 \mathrm{~cm}$ and weight $2.3 \pm 1.67 \mathrm{~g}$, with $404 \pm 99$ embryos at each gestation. In RJ, height was $9.69 \pm 1.05 \mathrm{~cm}$ and weight $2.9 \pm 0.9 \mathrm{~g}$, with the fecundity of $277 \pm$ 95.06 eggs per clutch, and for males, height was $10.06 \pm 1.02 \mathrm{~cm}$ and weight $3.68 \pm 1.18 \mathrm{~g}$, with the fecundity of $156.38 \pm 66$ embryos at each gestation. The equations obtained from the weight $(\mathrm{W})$ to height $(\mathrm{H})$ ratio were: $\mathrm{W}=0.002 \mathrm{H}^{3.182}, \mathrm{R}^{2}=0.947$ (RS males); $\mathrm{W}=0.004 \mathrm{H}^{2.914}, \mathrm{R}^{2}=0.949$ (RS females); $\mathrm{W}=0.0050 \mathrm{H}^{2.838}, \mathrm{R}^{2}=$ 0.793 (RJ males); $\mathrm{W}=0.014 \mathrm{H}^{2.355}, \mathrm{R}^{2}=0.733$ (RJ females). $\mathrm{RS}$ females produced more eggs $(P=0.023)$, and males incubated more embryos $(P=0.000)$ than those of RJ. The mean height of brood pouch formation in males was $4.69 \pm 0.48 \mathrm{~cm}, 95 \%$ CI $[4.53 ; 4.86]$, while the mean height at first sexual maturity was $8.34 \mathrm{~cm}$ (95\% CI [7.481; 9.046]). Alternative strategies need to be developed for the conservation of H. patagonicus in Brazil.
\end{abstract}

Keywords: Hippocampus patagonicus; seahorse; bycatch; fishing resources; reproduction; threatened species

\section{INTRODUCTION}

Although widely distributed, most seahorse species are threatened with extinction due to targeted fishing, bycatch and destruction of their habitats, which have a substantial impact on the delicate population structure of these species. Particular biological characteristics shared by species of the genus Hippocampus, such as monogamy, low population density and spotty distribution, low fecundity and local fidelity, among others, make the group even more susceptible not only to fishery or tourist overexploitation, but to various other anthropic changes occurring in the sea, estuaries and mangroves (Lourie et al., 2004; Silveira, 2005; Rosa et al., 2011; Vincent et al., 2011; Pujol, 2014).

Among the three species of seahorses that occur in Brazil (Silveira et al., 2014), Hippocampus reidi Ginsburg, 1933, which inhabits marine and estuarine waters, is the most studied (Silveira, 2000, 2005; Rosa et al., 2007; Mai \& Velasco, 2011; Silveira \& Silva, 2016; Silva et al., 2017; Siqueira et al., 2017). Regarding the other two species, Hippocampus erectus Perry, 1810 and Hippocampus patagonicus Piacentino \& Luzzatto, 2004, little is known about life history characteristics in Brazilian waters, since none of them are found in estuaries, where seahorses are more accessible and study less expensive than at sea. For $H$. erectus, for example, the only available data are records of occurrence at sea from the state of Rio Grande do Sul (RS) to Pará (Silveira et al., 2014) and basic biology information obtained in captivity (Silveira \& Silva, 2016).

H. patagonicus was described for west Bahia de San Antonio, in Argentine Patagonia (Piacentino \& Luzzatto, 2004), and its distribution has recently been extended to Brazil (Boehm et al., 2013; Silveira et al., 2014), where specimens of this species have been mistaken for $H$. erectus in Brazil (Figueiredo \&

Corresponding editor: Yassir Torres 
Menezes, 1980; Silveira, 2011; Silveira \& Oliveira, 2012; Silveira et al., 2014) and Uruguay (Nion et al., 2002). H. patagonicus can occur in an area of approximately $3,300 \mathrm{~km}$ from the coast between Argentina, Uruguay and Brazil. Nevertheless, in none of these countries, do we fully understand their distribution and life history. The three seahorse species recorded for Brazilian waters are listed in the official list of endangered species in Brazil, all in the "Vulnerable" (VU) category (MMA, 2014). At the global level, the International Union for Conservation of Nature (IUCN) evaluated $H$. reidi as "near threatened" (NT) and H. erectus and H. patagonicus as VU (IUCN, 2017).

The trade of $H$. patagonicus has been recorded in Argentina for decades (Pujol, 2014) and in Brazil, the species has also been marketed possibly with incorrect identification (Silveira, 2005; Rosa et al., 2011), due to the systematic confusion that existed until 2014 (Silveira et al., 2014).

In Argentina, $H$. patagonicus can be found in estuaries (Piacentino \& Luzzatto, 2004; Storero \& González, 2008), but in Brazil, this species occurs exclusively in the sea, where it has been collected as bycatch at depths between 11 and $57 \mathrm{~m}$ and a distance of 0.77 to $78 \mathrm{~nm}$ (nautical miles) from the coast (Silveira et al., 2018). More recent observations show H. patagonicus at depths of up to $100 \mathrm{~m}$ (Silveira, unpubl. data).

We aimed to estimate some aspects of the life history of the species such as height at first sex gonadal maturity, height of brood pouch formation in males, fecundity and fertility, with specimens from the pilot study on the presence of seahorses in trawls of the industrial and semi-industrial marine fishing in the states of RS and RJ. Finally, the paper aimed to provide information that helps public policies for the conservation of $H$. patagonicus in Brazil.

\section{MATERIALS AND METHODS}

Specimens of Hippocampus patagonicus from trawling bycatch were collected off the coast of RS, in southernmost Brazil, and on the coast of RJ, southeast region (Fig. 1), from February to November 2012 and November and December 2014, respectively. The biological material was collected according to Silveira et al. (2018) and came from two trawlers in RS and one in RJ.

The animals were fixed in absolute alcohol for analysis of the following parameters: fecundity (number of eggs per female), fertility (number of embryos per male), height $(\mathrm{H}$, linear measure of the top of the head to the tip of the stretched tail), weight-height ratio, mean height of brood pouch formation, mean height at first sexual maturity, sex ratio and head length/snout length ratio (HL/SNL). For juvenile specimens, with no apparent external secondary sexual characteristics, sex was established by analysis of the gonads under a stereoscopic microscope, according to the criteria of Vazzoler (1996).

The seahorses were identified according to Piacentino \& Luzzatto (2004) and Silveira et al. (2014), measured with a digital caliper $(0.5 \mathrm{~mm})$, and weighed on a semi-analytical scale (0.001 g). Female's eggs, as well as the embryos incubated by males, were counted under a stereomicroscope to estimate fecundity and mean fertility, respectively. HL/SNL was determined from the measurements taken with a digital caliper (Lourie et al., 1999). The correlation of weight and height with the number of eggs for females and the number of embryos for males was tested using the Kendall test (1938). To test the significance of any differences between the sexes, as for the measures of height, weight and HL/SNL ratio, and between the sampling sites, regarding number of eggs, number of embryos and HL/SNL, the Mann \& Whitney test (1947) and Student $t$-test (1908) were used, along with the binomial test for comparing sexual proportions. The software used was R, version 3.5.0 (R Core Team, 2018), and the level of significance was $5 \%$.

The mean height of the brood pouch formation was determined in juveniles, from the smallest male with a fully formed pouch to the largest male with the pouch still forming. Linear regression was applied where the variable indicating the formed brood pouch assumed a value of " 1 ", while the variable indicating the pouch still forming was "0" (Silveira \& Silva, 2016). For regression results that did not show a difference in height between the animals with the pouch still forming and the pouch already formed, we determined the mean, standard deviation and confidence interval (CI) at the 5\% level of significance of the same group of animals to obtain the mean height of brood pouch formation.

The equation of the weight-height relation was estimated by linear regression (log-log model), using a $5 \%$ level of significance. For this calculation, two ranges of heights were used: for juveniles, male or female, $\leq 6.0 \mathrm{~cm}$, and, for male or female adults, $\geq 6.1$ $\mathrm{cm}$. The choice for cutoff point $(6.1 \mathrm{~cm})$ was based on the height of the first male observed pregnant in RS. For RJ, since only adults were collected, this calculation was made considering the height range of the animals collected.

The mean height at first sexual maturity, in which $50 \%$ of the population is reproductive (Vazzoler, 1996), 


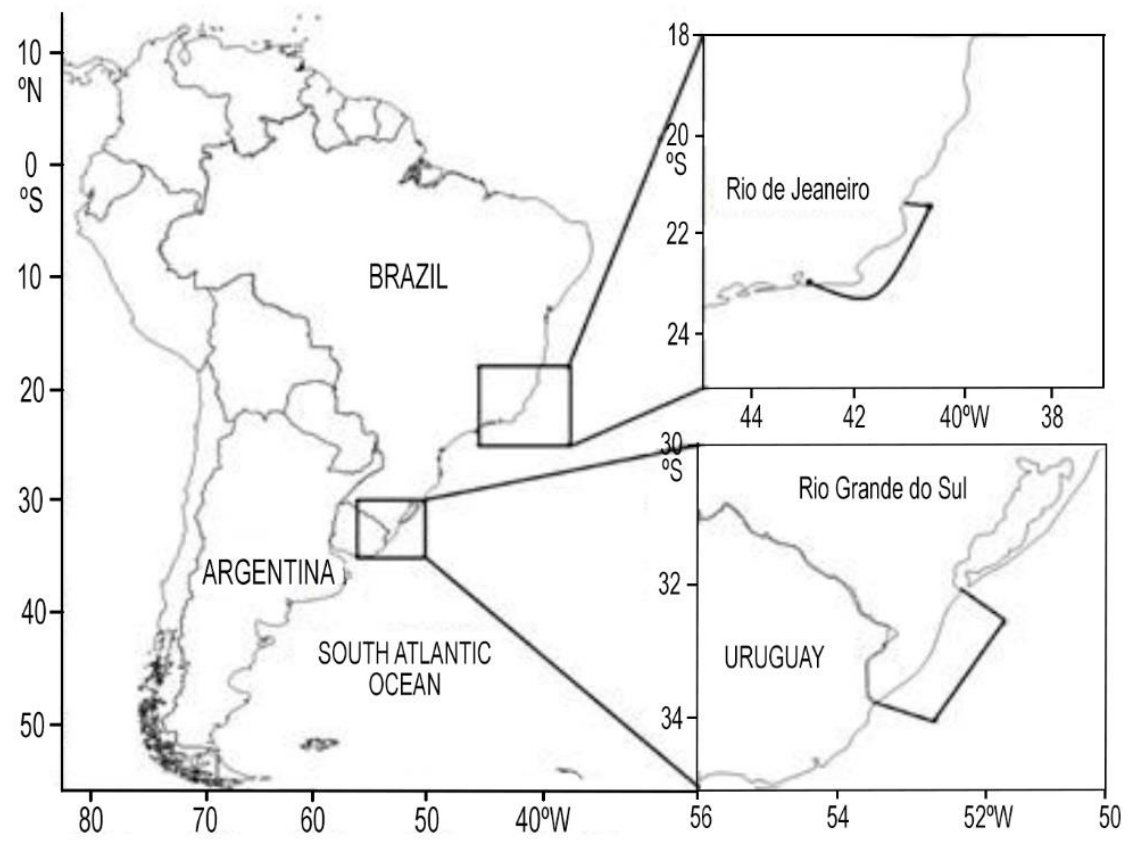

Figure 1. Sampling sites of Hippocampus patagonicus in the states of Rio Grande do Sul and Rio de Janeiro, Brazil.

was determined using the relative frequency of pregnant males according to height class, fitted to the following logistic function:

$$
F=\frac{1}{1+e^{-r\left(H_{t}-H_{m}\right)+b \times \text { location }}}
$$

Where $\mathrm{F}$ is the frequency of pregnant males per length class, $r$ is a parameter related to the rate of immature-mature state change, $\mathrm{H}_{\mathrm{t}}$ is body height, and $\mathrm{H}_{\mathrm{m}}$ is the estimated size at first gonadal maturity, Location is a binary variable used to separate the animals observed in RS (indicated by 1 ) and RJ (indicated by 0 ); $b_{i}$ is the parameter that indicates the difference in height at first maturation between animals from RS and RJ.

Fitting was done using the nonlinear regression routine of $\mathrm{R}$, version 3.5.0. with adjustment using the Levenberg-Marquardt algorithm. The same mean value at first gonadal maturity was assumed for males and females (Silveira, 2005; Silveira et al., 2016).

The weight to height ratio will be obtained through linear regression, where the weight variation is estimated as a function of the height of the seahorses, adopting a level of significance of 5\%. The weightheight equation $\left(\mathrm{W}=\mathrm{aH}^{\mathrm{b}}\right)$ will be adjusted according to Huxley (1924) using the least-squares method applied to the converted data in their respective natural logarithms.

\section{RESULTS}

\section{Rio Grande do Sul}

One hundred and ninety-nine seahorse specimens were collected, of which 197 were identified as Hippocampus patagonicus, one as $H$. reidi and one as $H$. erectus. Of the total $H$. patagonicus individuals, 92 were females, and 105 were males. There was no significant difference in the proportion between males and females for $H$. patagonicus $(P=0.3546)$. The height of the females varied between 2.5 and $13.0 \mathrm{~cm}$. The smallest ovate female showed a height of $5.1 \mathrm{~cm}$ and had 442 eggs, and the mean height of females of reproductive age was $8.89 \pm 1.9 \mathrm{~cm}$, while mean weight was $1.67 \pm 1.4 \mathrm{~g}$ and fecundity $366 \pm 195.8$ eggs per clutch $(\mathrm{n}=29)$. Male height varied between 2.6 and $13.0 \mathrm{~cm}$, and the mean height of males of reproductive age was $8.79 \pm 1.86 \mathrm{~cm}$, with a mean weight of $2.3 \pm$ $1.67 \mathrm{~g}$. Of the 105 male seahorses, 30 were of reproductive age, and 10 were pregnant, making it possible to estimate fertility of $404 \pm 99$ embryos per pregnancy.

The mean height of brood pouch formation was 4.69 $\pm 0.48 \mathrm{~cm}(95 \%$ CI $[4.53 ; 4.86])$. Young male seahorses $(2.6$ to $6.0 \mathrm{~cm}$ ) had a mean height of $4.064 \pm 0.825 \mathrm{~cm}$ and a weight of $0.266 \pm 0.171 \mathrm{~g}$, while females ( 2.5 to $5.9 \mathrm{~cm})$ had a mean height of $3.916 \pm 0.945 \mathrm{~cm}$ and weight of $0.272 \pm 0.221 \mathrm{~g}$, where there was no significant difference between the sexes $(P=0.242$ and 0.220 , for height and weight, respectively). 
Table 1. Estimation of the mean height at first gonadal maturity for Hippocampus patagonicus in the state of Rio Grande do Sul, Brazil. Setting curve using nonlinear regression - Levenberg-Marquard algorithm. r: linear correlation, $\mathrm{H}_{\mathrm{m}}$ : size at firt gonadal maturity.

\begin{tabular}{lccccc}
\hline \multirow{2}{*}{ Parameter } & \multirow{2}{*}{ Estimate } & \multirow{2}{*}{$\begin{array}{c}\text { Standard } \\
\text { deviation }\end{array}$} & \multicolumn{2}{c}{$\begin{array}{c}\text { Confidence } \\
\text { limit }(95 \%)\end{array}$} & \multirow{2}{*}{$P$} \\
\cline { 4 - 5 } & & & Lower & Upper & \\
\hline $\mathrm{r}$ & 0.536 & 0.278 & -0.122 & 1.194 & 0.112 \\
$\mathrm{~L}_{\mathrm{m}}$ & 8.515 & 0.841 & 6.526 & 10.505 & 0.000 \\
\hline
\end{tabular}

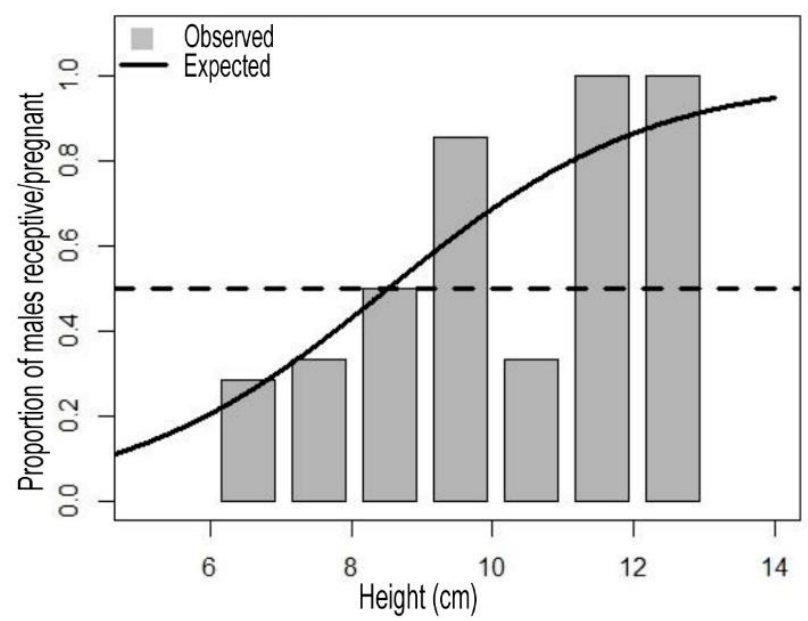

Figure 2. Height at first gonadal maturity of Hippocampus patagonicus collected in the state of Rio Grande do Sul, Brazil.

The analysis by height class of adult animals showed that between 8.1 and $9.0 \mathrm{~cm}, 50 \%$ of the males collected were pregnant, and the mean height at first gonadal maturity was estimated at $8.51 \mathrm{~cm}$ (Table 1 , Fig. 2).

Although the animals at reproductive age, found sexually mature, were captured in the months of February and March, it was not possible to estimate a reproductive period due to the lack of samplings in all months of the year, where these were limited to February ( $\mathrm{n}=112)$, March $(\mathrm{n}=35)$, April $(\mathrm{n}=14)$, May $(\mathrm{n}=5)$, July $(\mathrm{n}=14)$, August $(\mathrm{n}=10)$, October $(\mathrm{n}=5)$ and November $(n=2)$. The equations obtained for the weight-height relation are shown in Table 2.

The allometric coefficient of the males (3.182) showed a more pronounced growth in weight than in height, whereas for females, allometric growth was negative (2.914), non-significant difference to isometry $(P=0.3013$ and $P=0.6068$, respectively), close to isometric (3.0), that is, a proportional increase in weight and height. Juveniles of both sexes showed negative allometric growth, growing more in height than in weight.
Table 2. Equations of weight (W)-height $(\mathrm{H})$ relation for males and females of Hippocampus patagonicus collected in the state of Rio Grande do Sul, Brazil. $\mathrm{R}^{2}$ : coefficient of determination.

\begin{tabular}{lccc}
\hline Sex & $\begin{array}{c}\text { Height } \\
(\mathrm{cm})\end{array}$ & Equation & $\mathrm{R}^{2}$ \\
\hline Male & $\geq 6.1$ & $\mathrm{~W}=0.0022 \mathrm{H}^{3.182}$ & 0.947 \\
Male juvenile & $\leq 6.0$ & $\mathrm{~W}=0.0056 \mathrm{H}^{2.693}$ & 0.909 \\
Female & $\geq 6.1$ & $\mathrm{~W}=0.0039 \mathrm{H}^{2.914}$ & 0.949 \\
Female juvenile & $\leq 6.0$ & $\mathrm{~W}=0.0054 \mathrm{H}^{2.767}$ & 0.959 \\
\hline
\end{tabular}

The head length/snout length ratio showed no difference between the sexes $(P=0.472)$. When analyzed by height class, weight and height did not show significant differences between the sexes for males and females from the mean height at first gonadal maturity (weight, $P=0.592$ and height, $P=0.191$ ), nor for males and females below this value (weight, $P=0.220$ and height, $P=0.242$ ).

\section{Rio de Janeiro}

A total of 159 seahorses were collected, all identified as $H$. patagonicus, of which 57 were females, and 102 were males, with significantly more males $(P=0.000)$, and heights ranged from 7.2 to $12.5 \mathrm{~cm}$. The mean height of females of reproductive age was $9.689 \pm 1.05$ $\mathrm{cm}$, and weight was $2.95 \pm 0.9 \mathrm{~g}$, while fecundity was $277 \pm 95.06$ eggs per clutch $(n=57)$. The mean height of males of reproductive age was $10.06 \pm 1.02 \mathrm{~cm}$, and weight was $3.68 \pm 1.18 \mathrm{~g}$. The male seahorses were of reproductive age, and 73 were pregnant, making it possible to estimate fertility of $156.38 \pm 66$ embryos per pregnancy. The analysis by height class showed that between 8.1 and $9.0 \mathrm{~cm}, 54.5 \%$ of the males collected were pregnant, and the mean height at first sexual maturity was estimated at $8.39 \mathrm{~cm}$ (Table 3, Fig. 3).

It was not possible to determine the mean height of brood pouch formation due to the lack of juveniles in the samples. Although the animals of reproductive age were captured in November $(\mathrm{n}=124)$ and December $(\mathrm{n}$ $=35$ ), it was not possible to estimate a reproductive period due to lack of sampling in the other months of the year. The equations of weight to height ratio are shown in Table 4.

\section{Rio Grande do Sul $\times$ Rio de Janeiro}

The HL/SNL ratio showed no difference between the sexes from the same locality (Table 5), but this variable was lower in the RJ population (Table 6), suggesting a larger snout size for the seahorses of that state compared to RS. Similarly, the weight and height of males and females were higher in RJ than in RS, but RS specimens had more eggs and embryos than the RJ population (Table 5). 
Table 3. Estimation of the mean height at first gonadal maturity for Hippocampus patagonicus in the state of Rio de Janeiro, Brazil. Setting curve using nonlinear regression - Levenberg-Marquard algorithm. r: linear correlation, $\mathrm{H}_{\mathrm{m}}$ : size at firt gonadal maturity.

\begin{tabular}{lccccc}
\hline \multirow{2}{*}{ Parameter } & \multirow{2}{*}{ Estimate } & \multirow{2}{*}{$\begin{array}{c}\text { Standard } \\
\text { deviation }\end{array}$} & \multicolumn{2}{c}{$\begin{array}{c}\text { Confidence } \\
\text { limit }(95 \%)\end{array}$} & \multirow{2}{*}{$P$} \\
\cline { 4 - 5 } & & & Lower & Upper & \\
\hline $\mathrm{r}$ & 0.579 & 0.161 & 0.213 & 1.302 & 0.023 \\
$\mathrm{H}_{\mathrm{m}}$ & 8.392 & 0.415 & 6.090 & 9.373 & 0.000 \\
\hline
\end{tabular}

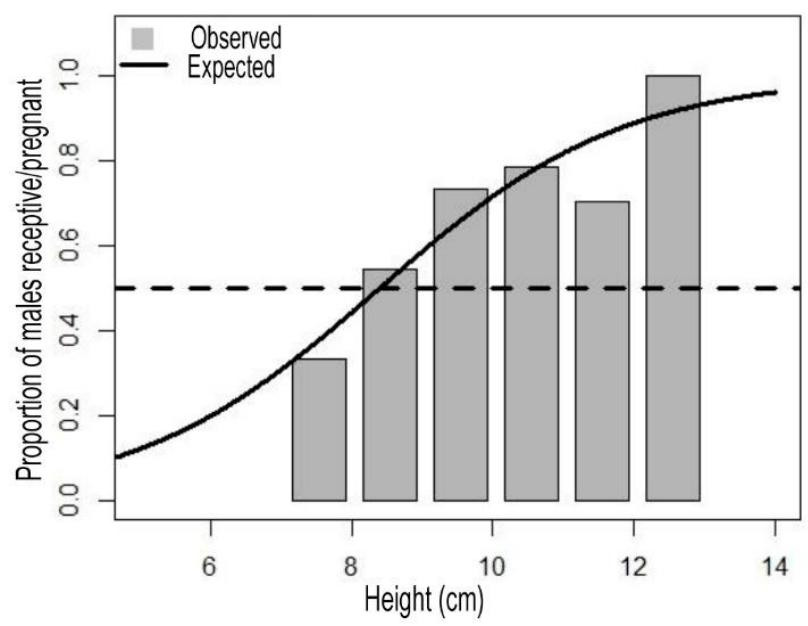

Figure 3. Height at first gonadal maturity of Hippocampus patagonicus collected in the state of Rio de Janeiro, Brazil.

For the RS sample, there was no correlation between weight or height with the number of eggs produced per clutch $(P=0.469$ and 0.427 , respectively), nor with the number of embryos incubated by the male $(P=0.381$ and 0.114; respectively), but there was a significant positive correlation between weight and height for males and females $(P<0.001)$. Likewise, in the RJ sample, there was no significant correlation between weight and height with the number of eggs produced per clutch $(P=0.469$ and 0.427 , respectively), nor with the number of embryos incubated by the male $(P=$ 0.381 and 0.111 , respectively). There was a positive correlation between weight and height for both males and females $(P<0.001)$. However, males showed higher weight and height than females in RJ (Table 5).

\section{Combined data at first gonadal maturity (RS+RJ)}

The proportion of pregnant males observed in $\mathrm{RJ}$ and RS was statistically similar, as was the mean height at first sexual maturity by location $(P>0.005)$. Accordingly, we combined the observed samples to fit a single nonlinear regression model for the estimation of the mean height at first sexual maturity for the species in Brazil (Table 7).
Table 4. Equations of weight (W)-height $(\mathrm{H})$ ratio for males and females of Hippocampus patagonicus collected in the state of Rio de Janeiro, Brazil. $\mathrm{R}^{2}$ : coefficient of determination.

\begin{tabular}{lccc}
\hline Sex & Height $(\mathrm{cm})$ & Equation & $\mathrm{R}^{2}$ \\
\hline Male & 7.5 & $\mathrm{~W}=0.005 \mathrm{H}^{2.838}$ & 0.793 \\
Female & 7.2 & $\mathrm{~W}=0.014 \mathrm{H}^{2.355}$ & 0.733 \\
\hline
\end{tabular}

\section{DISCUSSION}

A large number of seahorses whose biology is known are considered monogamous (Vincent, 1994; Kvarnemo et al., 2000; Foster \& Vincent, 2004; Silveira, 2005), and a paired sex rate of 1:1 is expected. However, different results occur and can be attributed to environmental conditions, seasons, fishing, or merely insufficient sampling. According to Pujol (2014), the population of Hippocampus patagonicus occurring in the Port of Mar del Plata, Argentina, showed a variable sex ratio, depending on the season of the year, but considering the entire sample in the several seasons, there was no difference between the sexes. Siqueira et al. (2017) studied a population of $H$. reidi in southern Brazil and found a similar sex ratio with no significant difference between the sexes. In the present study, the sample from RS, which was the best represented in all height classes, did not show any difference regarding sex ratio $(P=0.355)$, including the juveniles that had their gonads macroscopically analyzed. On examining height class, considering important events such as mean height at first gonadal maturity $(8.34 \mathrm{~cm})$, thus meaning operational sex ratio, i.e., mature males and females available for mating, there was no significant difference, corroborating a monogamous behavior. The condition factor revealed by the parameter "a" in the weight-height equation (Table 2), showed the highest values for the young age range, demonstrating better conditioning in juveniles compared to adults, which are already allocating their energies for reproduction/ gestation. The coefficient of determination $\left(\mathrm{R}^{2}\right)$ indicated that the size of the fish explains between 90 and $96 \%$ of the observed weight.

For the RJ sample, the sex ratio was firmly in favor of males, and the large difference (102 males: 57 females) could be explained by insufficient sampling (only two months of the collection), since proportions may vary with the season of the year (Pujol, 2014). The negative allometric coefficient for both sexes $(<3)$ showed greater development in height than weight, although males were heavier and taller than females, which showed a higher condition factor (Table 2). The coefficient of determination $\left(\mathrm{R}^{2}\right)$ indicated that the size of the fish explained $73-79 \%$ of the weight. 
Table 5. Comparison of the variables HL/SNL, height, and weight between the sexes in Hippocampus patagonicus. Values in bold indicate a significant difference. RS: Rio Grande do Sul, RJ: Rio de Janeiro.

\begin{tabular}{lcrc}
\hline \multirow{2}{*}{ Location/Variable } & \multicolumn{2}{c}{ Sex } & \multirow{2}{*}{$P$} \\
\cline { 2 - 3 } & Females & Males & \\
\hline RS & & & \\
HL/SNL & $3.762(0.520)$ & $3.742(0.522)$ & 0.472 \\
Height & $8.892(1.902)$ & $8.790(1.832)$ & 0.824 \\
Weight & $2.106(1.498)$ & $2.297(1.632)$ & 0.940 \\
RJ & & & \\
HL/SNL & $3.401(0.256)$ & $3.381(0.436)$ & 0.526 \\
Height & $9.686(1.058)$ & $10.067(1.028)$ & $\mathbf{0 . 0 2 9}$ \\
Weight & $2.957(0.907)$ & $3.679(1.180)$ & $\mathbf{0 . 0 0 0}$ \\
\hline
\end{tabular}

Table 6. Comparison of the variables HL/SNL, height, and weight between the locations of Hippocampus patagonicus. Values in bold indicate a significant difference.

\begin{tabular}{lccc}
\hline \multirow{2}{*}{ Variable } & \multicolumn{2}{c}{ Local } & \multirow{2}{*}{$P$} \\
\cline { 2 - 3 } & RS & RJ & \\
\hline HL/SNL (females) & $3.762(0.520)$ & $3.401(0.256)$ & $\mathbf{0 . 0 0 0}$ \\
HL/SNL (males) & $3.742(0.522)$ & $3.381(0.436)$ & $\mathbf{0 . 0 0 0}$ \\
Height (females) & $8.892(1.902)$ & $9.686(1.058)$ & $\mathbf{0 . 0 2 6}$ \\
Weight (females) & $2.106(1.498)$ & $2.957(0.907)$ & $\mathbf{0 . 0 0 2}$ \\
Height (males) & $8.790(1.832)$ & $10.067(1.028)$ & $\mathbf{0 . 0 0 1}$ \\
Weight (males) & $2.297(1.632)$ & $3.679(1.180)$ & $\mathbf{0 . 0 0 0}$ \\
Number of eggs & $366.600(195.860)$ & $227.680(95.070)$ & $\mathbf{0 . 0 2 3}$ \\
Number of embryos & $404.110(99.230)$ & $156.380(66.620)$ & $\mathbf{0 . 0 0 0}$ \\
\hline
\end{tabular}

Table 7. Estimation of the mean height at first gonadal maturity for Hippocampus patagonicus in Brazil. Setting curve using nonlinear regression - Levenberg-Marquard algorithm. $\mathrm{r}$ : linear correlation, $\mathrm{H}_{\mathrm{m}}$ : size at firt gonadal maturity.

\begin{tabular}{lccccc}
\hline \multirow{2}{*}{ Parameter } & Estimate & $\begin{array}{r}\text { Standard } \\
\text { deviation }\end{array}$ & \multicolumn{2}{c}{$\begin{array}{c}\text { Confidence } \\
\text { limit }(95 \%)\end{array}$} & $P$ \\
\cline { 4 - 5 } & & & Lower & Upper & \\
\hline $\mathrm{r}$ & 0.572 & 0.105 & 0.341 & 0.923 & 0.0028 \\
$\mathrm{H}_{\mathrm{m}}$ & 8.342 & 0.286 & 7.481 & 9.046 & 0.0000 \\
\hline
\end{tabular}

Comparisons among populations regarding weight and height data suggest that individuals in RJ are larger and heavier than those in RS. However, this result should be viewed with caution, since in RJ, only adult specimens were collected, it is possible to have been some sampling bias. The maximum height of a species does not appear to vary with latitude, although $H$. abdominalis exhibited greater height at higher latitudes, which may represent a response to temperature variation (Foster \& Vincent, 2004). In general, seahorses also do not display differences in size between the sexes (Foster \& Vincent, 2004; Silveira, 2005; Pujol, 2014; Siqueira et al., 2017), as seen in the RS sample. Concerning weight, however, males are expected to be heavier than females, due to the development of the brood pouch (Lovett, 1969; Vincent, 1990; Filleul, 1996; Silveira, 2005; Silveira \& Fontoura, 2010). In the RJ sample, males were larger and heavier than females (Table 4), and in both RJ and RS, females had a higher condition factor than males. Possibly this is due to the fact that males carry the developing eggs after mating in addition to supporting the weight of their brood pouch, and bear the energy cost of the complex physiology of embryo nutrition (Linton \& Soloff, 1964; Boisseau, 1967; Azzarello, 1991; Melamed et al., 2005). Silveira (2005) reported a lower weight of $1.62 \pm 0.89 \mathrm{~g}$ in $\mathrm{H}$. reidi males after releasing the offspring from the brood pouch $(n=5)$.

The difference in height between the sexes in the RJ sample was possibly a reflection of the sex ratio, which was strongly male-biased, with insufficient or sampling bias as an explanation.

The highest fecundity and fertility rates shown by the RS population about RJ might have been related to the higher latitudes, and it is believed that the size of the clutch does not decrease with latitude as compensation for the larger size of the egg and the juvenile (Foster \& Vincent, 2004). On the other hand, a negative correlation was observed between clutch size and egg size for various taxa, such as fish (Duarte \& Alcaraz, 1989; Elgar, 1990), copepods (Poulin, 1995), 
turtles (Elgar \& Heaphy, 1989) and birds (Lack, 1968; Blackburn, 1991). The groups showed a larger clutch at higher latitudes, which would be related to a more extended photoperiod and maintenance costs associated with high temperatures (Fleming \& Gross, 1990), with natural selection making the balance between many small eggs with less probability of survival versus a few larger eggs of higher quality and greater probability of survival. For example, for Pacific salmon (Oncorhynchus spp.), it was observed that fecundity increased with latitude, but that egg size decreased as compensation, while smaller eggs and fry at lower latitudes would result from maintenance costs associated with high temperatures (Drucker, 1972; Crone \& Bond, 1976; Beacham, 1982; Healey \& Heard, 1984). Populations of the same northern salmon species produced 38\% more eggs than did southern populations (Fleming \& Gross, 1990). In the present study, $H$. patagonicus females of RS produced $39.53 \%$ more eggs compared to those of RJ, and RS males incubated $61.3 \%$ more embryos compared to RJ males, although the sample of adults and in maturation/mature fish from $\mathrm{RS}$ was smaller than those of RJ.

The brood pouch, present in males, is a character of sexual dimorphism in seahorses. The mean height of brood pouch formation is a measure of fundamental importance because, together with other life-history data, it allows the visualization of the population structure of the species, favoring animal management decisions (Baum et al., 2003; Silveira, 2005; Silveira et $a l ., 2016)$. Preliminary data suggest that for $H$. reidi, the formation of the brood pouch varies with latitude, and there appears to be a latitudinal gradient directly related to the development of the animal, that is, the lower the latitude, the slower the development (Silveira et al., 2016). Studies of several species of fish with broad distribution bands have shown that juvenile growth rates are faster at higher latitudes, where the growing season is shorter, influenced mainly by temperature (Winemiller, 1995). The annual mean sea surface temperature is $23.73^{\circ} \mathrm{C}$ in $\mathrm{RJ}, 19.02^{\circ} \mathrm{C}$ in $\mathrm{RS}$, and decreases as latitude increases (Table 8, Fig. 4).

The results suggest that the difference in temperature ranges between RS and RJ was not enough to influence the mean height at first gonadal maturity since the values shown by the populations of the two regions were similar, even with the presence of a marked seasonality in RS.

On the other hand, similar measures of height at first gonadal maturity do not necessarily mean that the individuals are of the same age. Populations of $H$. trimaculatus from southern and northern China, for example, mature at the same size but with an age difference of about two months (Wilson \& Vincent, 1998). The southernmost part of South America for which
Table 8. Comparison of mean annual seawater temperature $\left({ }^{\circ} \mathrm{C}\right)$ at cities of occurrence for Hippocampus patagonicus in Brazil (BR) and Argentina (AR) (www.seatemperatura.org). Different superscript letters in the column indicate significant differences $(P<0.05)$.

\begin{tabular}{lccc}
\hline Local & Mean & $\begin{array}{c}\text { Standard } \\
\text { deviation }\end{array}$ & $P$-value \\
\hline Puerto Madryn-AR & $13.29^{\mathrm{c}}$ & 2.95 & 0.000 \\
San Antonio Oeste-AR & $14.71^{\mathrm{c}}$ & 3.15 & \\
Rio Grande (RS)-BR & $19.02^{\mathrm{b}}$ & 3.94 & \\
Rio de Janeiro (RJ)-BR & $23.73^{\mathrm{a}}$ & 1.39 & \\
Mar del Plata-AR & $15.18^{\mathrm{bc}}$ & 3.76 & \\
\hline
\end{tabular}

occurrence of $H$. patagonicus is cited is Puerto Madryn, Argentina $\left(42^{\circ} \mathrm{S}\right)$ where the mean annual sea surface temperature is $13.29^{\circ} \mathrm{C}$ and where $H$. patagonicus showed a height at first sexual maturity of $11 \mathrm{~cm}$ (Wei et al., 2017).

According to the HL/SNL index, specimens of $H$. patagonicus (males and females) from southern Brazil (RS) showed a significantly shorter snout (HL/SNL $3.76 \pm 0.52)$ compared to RJ $(3.40 \pm 0.25)$, while the Argentinian specimens displayed a higher index compared to those from RS, $4.36 \pm 1.23$ (Piacentino \& Luzzatto, 2004), indicating an even smaller snout.

Relevant studies describe the snout size of the Syngnathidae concerning its predatory behavior, hydrodynamic morphology, diet and trophic position, food ontogenetic differences and resource availability (Teixeira \& Musick, 2001; Castro et al., 2008; Gurkan et al., 2011; Pereira, 2016). Known as "pivot feeders," seahorses can orchestrate synergistic movements using their unique anatomy and performing a dorsal head rotation and snout spin that allow them to reach prey faster and at a greater distance, directly influencing the success of the catch. It has also been observed that shorter and wider snouts are specific to animals with more sedentary habits and that they consume larger prey, whereas the longer and thinner snouts are to obtain smaller and faster prey (Lussanet \& Muller, 2007; Roos et al., 2010; Manning, 2017). The results obtained in the present study, compared to literature data, demonstrate intraspecific differences in the snout size of $H$. patagonicus. The variation in the snout size of $H$. patagonicus from RJ to Patagonia (San Antonio Oeste) suggests a latitudinal gradient that would be supported by temperature. Regardless of diet, a shorter snout in colder waters (in winter in San Antonio Oeste, the surface water, temperature is as low as $6^{\circ} \mathrm{C}$ ) would be more advantageous because of the relatively less difficulty of keeping it oxygenated and "warmed" enough to perform its vital function of feeding the individual and maintaining its life. It is well known according to general physiology, that blood vessels contract in the 

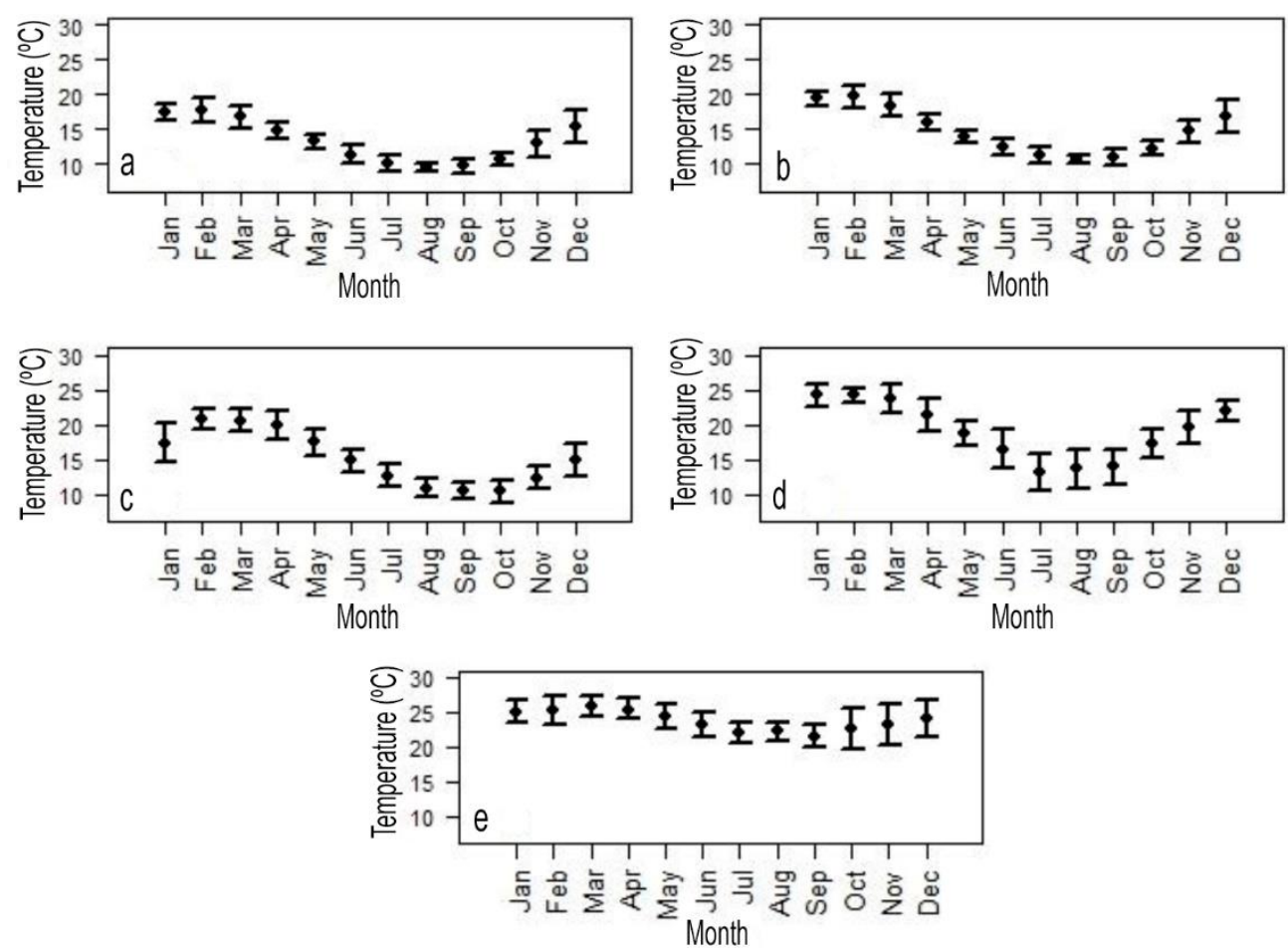

Figure 4. Mean annual temperature $\left({ }^{\circ} \mathrm{C}\right)$ of seawater surface at a) Puerto Madrin-AR, b) San Antonio Oeste-AR, c) Mar del Plata-AR, d) Rio Grande do Sul-BR, and e) Rio de Janeiro-BR.

cold and that the extremities are the most affected parts of the body with the lack of oxygenation and heat to maintain their functions, especially the enzymatic systems (Schmidt-Nielsen, 2002). Thus, a shorter and broader snout could be an advantage for seahorses living in colder waters by exposing a smaller surface to intense cold.

Argentina and Brazil share many fisheries resources, such as hake, Merluccius hubbsi (Merluccidae). Fishery biology studies have identified that the southeastern hake stock (between 21 and $29^{\circ} \mathrm{S}$ ) is distinct from the southern stock (between 29 and $34^{\circ} \mathrm{S}$, shared with Uruguay and Argentina) (Vaz-dosSantos et al., 2009). The lack of biological data on $H$. patagonicus, both in Argentina and Brazil, does not allow conclusions about the dynamics of the species' stocks. However, the vast extent of occurrence of $H$. patagonicus $(3,300 \mathrm{~km}$ from Argentina to the southeast of Brazil) and life history characteristics common to seahorses (monogamy, low population density, low fecundity, local fidelity and spotty distribution) suggest that populations are less dispersive and more susceptible to isolation and population segregation events, despite its planktonic phase and the dispersion through floating substrates (Luzzatto et al., 2013). The fact that $H$. patagonicus reaches sexual maturity at 11 $\mathrm{cm}$ in Mar del Plata (Wei et al., 2017) and $8.34 \mathrm{~cm}$ in
Brazil, as well as differences in the length of the snout shown by the populations of Argentina and south and southeast Brazil, may indicate that this species shows stocks with distinct characteristics along the west coast of the Atlantic. These results demonstrate the need for further studies on $\mathrm{H}$. patagonicus, including molecular investigations, to better understand the genetic variability of the species in its area of occurrence.

\section{CONCLUSIONS AND SUGGESTIONS}

The results of the present study represent the first data on the biology of Hippocampus patagonicus in Brazilian waters. In Brazil, there are some programs focused on the conservation of seahorses. The National Action Plan for the Conservation of Coral Environments (PAN Corais) is an initiative of the Brazilian government aimed at the conservation of biogenic reefs, sandstones and rocky shrublands with the presence of corals, from shallow waters to great depths and that shelter a considerable diversity of species of fauna and flora. Among the various species to be protected, called target species of PAN Corais, and listed in the list of endangered species, are seahorses. The data on $H$. patagonicus bycatch (Silveira et al., 2018) and the biology data presented in this study point to the need for alternative conservation strategies 
beyond those presented to date, considering that $H$. patagonicus does not occur in coral environments protected by PAN Corais. Conservation strategies should be expanded not only to include $H$. patagonicus, but also $H$. erectus, whose biology is poorly known in Brazil. For this species, we do not even know its location or settlement areas, because they rarely appear during monitoring dives or bycatch, never being found in abundance. A joint effort between researchers and government will be necessary to learn about the distribution and life history of these species and then to protect them adequately.

For $H$. reidi, a species that occurs in the marine environment and the mangrove swamps, PAN Corais can be involved, and it would be prudent and necessary to include it in PAN Manguezal too, since it is the habitat where its occurrence and density are higher, and since we do not know yet if the population(s) of the sea can be considered genetically the same as that in the mangrove. It will be of fundamental importance with the bioecological and distribution data of the species, the knowledge of the genetic diversity for the evaluation of its real state of conservation.

\section{ACKNOWLEDGMENTS}

We thank Petrobras Socioambiental and Annenberg Foundation for funding the study. We are grateful to ICMBio for authorization $\mathrm{N}^{\circ} 26566-3$, João Otavio Silveira for collecting the material in Porto de Rio Grande (RS) and Lara Vidon and Natália Barcelos for collecting the material in Porto de Niterói (RJ). We thank Dr. Marco Azevedo-FZBRS for the critical reading of the manuscript and offering excellent suggestions. Dr. A. Leyva (USA) provided English translation and editing of the manuscript.

\section{REFERENCES}

Azzarello, M.Y. 1991. Some questions concerning the Syngnathidae brood pouch. Bulletin of Marine Science, 49(3): 741-747.

Baum, J.K., Meeuwig, J.J. \& Vincent, A.C.J. 2003. Bycatch of lined seahorses (Hippocampus erectus) in a Gulf of Mexico shrimp trawl fishery. Fishery Bulletin, 101(4): 721-731.

Beacham, T.D. 1982. Fecundity of coho salmon (Oncorhynchus kisutch) and chum salmon (O. keta) in the northeast Pacific Ocean. Canadian Journal of Zoology, 60(6): 1463-1469.

Blackburn, T.M. 1991. An interspecific relationship between egg size and clutch size in birds. The Auk, 108: 973-977.
Boehm, J.T., Woodall, L., Teske, P.R., Lourie, S.A., Baldwin, C., Waldman, J. \& Hickerson, M. 2013. Marine dispersal and barriers drive Atlantic seahorse diversification. Journal of Biogeography, 40(10): 111.

Boisseau, J. 1967. Recherche sur le controle hormonal de l'incubation chez l'hippocampe. Revue Européen d'Endocrinologie, 4(3): 197-234.

Castro, A.L.C., Diniz, A.F., Martins, I.Z., Vendel, A.L., Oliveira, T.P.R. \& Rosa, I.M.L. 2008. Assessing diet composition of seahorses in the wild using a nondestructive method: $P$. reidi (Teleostei: Syngnathidae) as a study case. Neotropical Ichthyology, 6(4): 637-644.

Crone, R.A. \& Bond, C.E. 1976. Life history of coho salmon, Oncorhynchus kisutch, in Sashin Creek, southeastern Alaska. National Oceanic and Atmospheric Administration. Fishery Bulletin, 74: 897-923.

Drucker, B. 1972. Some life history characteristics of coho salmon of the Karluk River, Kodiak Island, Alaska. National Oceanic and Atmospheric Administration. Fishery Bulletin, 70: 79-94.

Duarte, C.M. \& Alcaraz, M. 1989. To produce many small or few large eggs: a size-independent reproductive tactic of fish. Oecologia, 80(3): 401-404.

Elgar, M.A. 1990. Evolutionary compromise between a few large and many small eggs: comparative evidence in teleost fish. Oikos, 59(2): 283-287.

Elgar, M.A. \& Heaphy, L.J. 1989. Covariation between clutch size, egg weight, and egg shape: comparative evidence for chelonians. Journal of Zoology, 219(1): 137-152.

Figueiredo, J.L. \& Menezes, N.A. 1980. Manual de peixes marinhos do sudeste do Brasil. III. Teleostei (2). Museu de Zoologia da Universidade São Paulo, São Paulo, 90 pp.

Filleul, M.A. 1996. Optimizing growth of juvenile bigbellied seahorse $P$. abdominalis Lesson. Thesis for Bachelor of Science Applied, University of Tasmania, Tasmania.

Fleming, I.A. \& Gross, M.R. 1990. Latitudinal clines: a trade-off between egg number and size in Pacific salmon. Ecology, 71(1): 1-11.

Foster, S.J. \& Vincent, A.C.J. 2004. Life history and ecology of seahorses: implications for conservation and management. Journal of Fish Biology, 65(1): 1-61.

Gurkan, S., Taskavak, E., Sever, T.M. \& Akalin, S. 2011. Gut contents of two European seahorses $P$. hippocampus and $P$. guttulatus in the Aegean Sea, coasts of Turkey. Pakistan Journal of Zoology, 43(6): 1197-1201. 
Healey, M.C. \& Heard, W.R. 1984. Inter- and intrapopulation variation in the fecundity of chinook salmon (Oncorhynchus tshawytscha) and its relevance to life-history theory. Canadian Journal of Fisheries and Aquatic Sciences, 41(3): 476-483.

Huxley, J.S. 1924. Constant differential growth-ratios and their significance. Nature 14: 896-897.

International Union for Conservation of Nature (IUCN). 2017. IUCN Red list of threatened species. Version 2017.3. [http://www.iucnredlist.org]. Reviewed: August 29, 2018.

Kendall, M. 1938. A new measure of rank correlation. Biometrika, 30(1-2): 81-89.

Kvarnemo, C., Moore, G.I., Jones, A.G., Nelson, W.S. \& Avise, J.C. 2000. Monogamous pair bonds and mate switching in the western Australian seahorse $P$. subelongatus. Journal of Evolutionary Biology, 13(6): 882-888.

Lack, D. 1968. Ecological adaptations for breeding in birds. Methuen, London.

Linton, J.R. \& Soloff, B.L. 1964. The physiology of the brood pouch of the male sea horse $P$. erectus. Bulletin of Marine Science, 14(1): 45-61.

Lourie, S., Vincent, A.C.J. \& Hall, H.J. 1999. Seahorses: an identification guide to the world's species and their conservation. Project Seahorse, London.

Lourie, S.A., Foster, S.J., Cooper, E.W.T. \& Vincent, A.C.J. 2004. A guide to the identification of seahorses. Project seahorses \& TRAFFIC North America University of British Columbia and World Wildlife Fundation, Columbia.

Lovett, J.M. 1969. An introduction to the biology of the seahorse $H$. abdominalis. University of Tasmania, Tasmania, $102 \mathrm{pp}$.

Lussanet, M.H.E. \& Muller, M. 2007. The smaller your mouth, the longer your snout: predicting the snout length of Syngnathus acus, Centriscus scutatus, and other pipette feeders. Journal of the Royal Society Interface, 4(14): 561-573.

Luzzatto, D.C., Estalles, M.L. \& Díaz de Astarloa, J.M. 2013. Rafting seahorses: the presence of juvenile Hippocampus patagonicus in floating debris. Journal of Fish Biology, 83(3): 677-681.

Mai, A.C.G. \& Velasco, G. 2011. Population dynamics and reproduction of wild longsnout seahorse $P$. reidi. Journal of the Marine Biological Association of the United Kingdom, 92(2): 421-427.

Mann, H.B. \& Whitney, D.R. 1947. On a test of whether one of two random variables is stochastically larger than the other. Annals of Mathematical Statistics, 18(1): 50-60.

Manning, C.G. 2017. How is a family of sedentary marine fishes shaped by its habitats, prey, and predators?
Ph.D. Thesis in Zoology. University of British Columbia, Columbia, 175 pp.

Melamed, P., Xue, Y., Poon, J.F.D., Wu, Q., Xie, H., Yeo, J., Foo, T.W. \& Chua, H.K. 2005. The male seahorse synthesizes and secretes a novel C-type lectin into the brood pouch during early pregnancy. FEBS Journal, 272(5): 1221-1235.

Ministério do Meio Ambiente (MMA). 2014. Portaria 445, de 17 de dezembro de 2014. Lista Nacional Oficial de Espécies da Fauna Ameaçadas de Extinção - Peixes e Invertebrados Aquáticos. Diário Oficial da União, 11 pp.

Nion, H., Ríos, C. \& Meneses, P. 2002. Peces del Uruguaylista sistemática y nombres comunes. Dirección Nacional de Recursos Acuáticos/INFOPESCA, Montevideo, $115 \mathrm{pp}$.

Pereira, L.F. 2016. Ecologia alimentar de Hippocampus patagonicus Piacentino \& Luzzatto, 2004 e a conservação de cavalos-marinhos (Teleostei : Syngnathidae) no Sul do Brasil. M.Sc. Thesis in Biological Sciences, Universidade Federal do Paraná, Curitiba, 97 pp.

Piacentino, G. \& Luzzatto, D. 2004. P. patagonicus sp. nov., nuevo caballito de mar para la Argentina (Pisces, Syngnathiformes). Revista del Museo Argentino de Ciencias Naturales, 6(2): 339-349.

Poulin, R. 1995. Clutch size and egg size in free-living and parasitic copepods: a comparative analysis. Evolution, 49(2): 325-336.

Pujol, M.G. 2014. Ecología del caballito de mar $P$. patagonicus (Piacentino \& Luzzatto, 2004) en las costas de Mar del Plata y su relación con ambientes impactados antrópicamente. Ph.D. Thesis in Marine Sciences. Universidad Nacional de Mar del Plata, Mar del Plata, $286 \mathrm{pp}$.

R Core Team. 2018. R: a language and environment for statistical computing. $\mathrm{R}$ foundation for statistical computing. [http://www.R-project.org]. Reviewed: June12, 2018.

Roos, G., Van Wassenbergh, S., Herrel, A., Adriaens, D. \& Aerts, P. 2010. Snout allometry in seahorses: insights on optimization of pivot feeding performance during ontogeny. Journal of Experimental Biology, 213(13): 2184-2193.

Rosa, I.L., Oliveira, T.P.R., Castro, A.L.C., Moraes, L.E.S., Xavier, J.H.A. \& Nottingham, M.C. 2007. Population characteristics, space use and habitat associations of the seahorse $P$. reidi (Teleostei: Syngnathidae). Neotropical Ichthyology, 5(3): 405414.

Rosa, I.L., Oliveira, T.P.R., Osório, F.M., Moraes, L.E., Castro, A.L.C., Barros, G.M.L. \& Alves, R. 2011. Fisheries and trade of seahorses in Brazil: historical perspective, current trends, and future directions. Biodiversity and Conservation, 20(9): 1951-1971. 
Schmidt-Nielsen, K. 2002. Fisiologia animal: adaptação e meio ambiente. Livraria Santos Editora, São Paulo.

Silva, H.B.F., Silva, R.R., Carneiro, N.V.Q., Pires, A.O., Machado, M.S.S., Marques, C.R. \& Costa, R. 2017. Hippocampus reidi extract, a marine natural product, attenuates NF-kB expression and suppresses inflammatory activity in vitro and in vivo. International Journal of Applied Research in Natural Products, 10: 1-14.

Silveira, R.B. 2000. Desenvolvimento osteológico de $P$. reidi Ginsburg (Pisces, Syngnathiformes, Syngnathidae), em laboratório: I. Período embrionário. Revista Brasileira de Zoologia, 17(2): 505-513.

Silveira, R.B. 2005. Dinâmica populacional do cavalomarinho $P$. reidi (Syngnathidae) no manguezal de Maracaípe, Ipojuca, PE. Ph.D. Thesis in Zoology, Pontifícia Universidade Católica do Rio Grande do Sul, Porto Alegre, 129 pp.

Silveira, R.B. 2011. Registros de cavalos-marinhos (Syngnathidae: Hippocampus) ao longo da costa Brasileira. Oecologia Australis, 15(2): 316-325.

Silveira, R.B. \& Fontoura, N.F. 2010. Fecundity and fertility of the longsnout seahorse, Hippocampus reidi (Teleostei: Syngnathidae), in tropical Brazil. Revista Brasileira de Biociências, 8(4): 362-367.

Silveira, R.B. \& Oliveira, C. 2012, Taxonomic revision of the genus Hippocampus Rafinesque, 1810 in Brazil. Anais do Simpósio Latino-Americano de Coleções Biológicas e Biodiversidade: Conhecimento e Gestão. Instituto Oswaldo Cruz, Rio de Janeiro, 138 pp.

Silveira, R.B. \& Silva, J.R.S. 2016. Growing the threatened seahorse Hippocampus erectus Perry 1810 in the laboratory. International Journal of Oceanography and Marine Biology, 3(1): 93-101.

Silveira, R.B., Silva, J.R.S. \& Ferreira-Fontoura, N. 2016. Reproductive period, average height for the development of the brood pouch and sexual maturation of the seahorse Hippocampus reidi (Syngnathidae) in the northeast of Brazil. Asian Academic Research Journal of Multidisciplinary, 3(3): 140-155.

Silveira, R.B., Siccha-Ramirez, R., Silva, J.R.S. \& Oliveira C. 2014. Morphological and molecular evidence for the occurrence of three Hippocampus species (Teleostei: Syngnathidae) in Brazil. Zootaxa, 3861(4): 317-332.

Received: 5 March 2019; Accepted: 16 July 2019
Silveira, R.B., Barcelos, B.T., Machado, R., Oliveira, L. \& Silva, J.R.S. 2018. Records of bycatch of Hippocampus patagonicus (Pisces: Syngnathidae) in commercial fishing in southern Brazil. Latin American Journal of Aquatic Research, 46(4): 744-755.

Siqueira, A.C., Quimbayo, J.P., Cantor, M., Silveira, R.B. \& Daura-Jorge, F.G. 2017. Estimating population parameters of longsnout seahorses, Hippocampus reidi (Teleostei: Syngnathidae) through mark-recapture. Neotropical Ichthyology, 15(4): 1-7.

Storero, L.P. \& González, R.A. 2008. Feeding habits of the seahorse Hippocampus patagonicus in San Antonio Bay (Patagonia, Argentina). Journal of the Marine Biological Association of the United Kingdom, 88(7): 1503-1508.

Student. 1908. The probable error of a mean. Biometrika, 6: $1-25$.

Teixeira, R.L. \& Musick, J.A. 2001. Reproduction and food habits of the lined seahorse, Hippocampus erectus (Teleostei: Syngnathidae) of Chesapeake Bay, Virginia. Revista Brasileira de Biologia, 61(1): 79-90.

Vaz-dos-Santos, A.M., Rossi-Wongtschowski, C.L.D.B. \& Figueiredo, J.L. 2009. Merluccius hubbsi (Teleostei: Merlucciidae): stock identification based on reproductive biology in the south-southeast Brazilian region. Brazilian Journal of Oceanography, 57(1): 17-31.

Vazzoler, A.E. 1996. Biologia da reprodução de peixes teleósteos: teoria e prática. EDUEM, São Paulo.

Vincent, A. 1990. Reproductive ecology of seahorses. University of Cambridge, Cambridge.

Vincent, A. 1994. Operational sex ratio in seahorses. Behavior, 128(1-2): 153-167.

Vincent, A., Foster, S.J. \& Koldewey, H.J. 2011. Conservation and management of seahorses and other Syngnathidae. Journal of Fish Biology, 78(6): 16811724.

Wei, J., Estalles, M., Pollom, R. \& Luzzatto, D. 2017. Hippocampus patagonicus, Patagonian Seahorse. IUCN Red List of Threatened Species, e.T195100A 54909767.

Wilson, M. \& Vincent, A. 1998. Preliminary success in closing the life cycle of exploited seahorses species, Hippocampus spp. in captivity. Aquarium Science and Conservation, 2: 179-196.

Winemiller, K.O. 1995. Fish ecology. In: Nierenberg, W.A. (Ed.). Encyclopedia of environmental biology. Academic Press, New York, pp. 49-65. 